\title{
3D electroanatomical mapping is less sensitive to atrial remodeling in estimation of true left atrial volume than echocardiography
}

\author{
Zdenka Fingrova ${ }^{1}$, Josef Marek${ }^{1}$, Stepan Havranek ${ }^{1 *} \mathbb{D}$, Lukas Lambert ${ }^{2}$, Petr Kuchynka ${ }^{1}$ and Ales Linhart ${ }^{1}$
}

\begin{abstract}
Background: Left atrial (LA) enlargement has been identified as a predictor of worse clinical outcome after catheter ablation for atrial fibrillation (AF). We investigated the correspondence of LA size parameters assessed by echocardiography, CT and 3D electroanatomical mapping in patients with AF treated by catheter ablation.

Methods: We analyzed echocardiographic LA volume measurements by disc summation method ( $L A V_{\text {DISC }}$, computed tomography $\left(L A V_{C T}\right)$ and 3D electroanatomical mapping (LAV $\left.\mathrm{VARTO}_{\text {CAn }}\right)$ in 100 pts. (71\% males; aged $63 \pm$ 8 years; paroxysmal AF in 55\% of patients).

Results: Mean LAV DIsC was $83 \pm 25 \mathrm{ml}$ (median: 115; IQR: 98-140 ml), mean LAV $\mathrm{CT}_{\mathrm{CT}}$ was $120 \pm 34 \mathrm{ml}$ (median: 115; IQR: 98-140 ml) and mean LAV ${ }_{\text {CARTO }}$ was $123 \pm 36 \mathrm{ml}$ (median: 118; IQR: 99-132 ml). Pearson's correlation coefficient between LAV DISC a LAV There was a significant difference between the two correlation coefficients $(p<0.004)$. The absolute difference between $L A V_{\text {CARTO }}$ and $\operatorname{LAV}_{C T}(3.5(95 \% \mathrm{Cl}-42-43) \mathrm{ml})$ was significantly lower $(p<0.0001)$ as compared to LAV DISC and $L A V_{C T}(-39$ (95\% Cl -102 - 24) ml). In opposite to LAV DISC, the bias between LAV obtained by CT and CARTO did not differentiate according to presence of spherical remodeling (1.7 \pm 28 vs. vs. $5.1 \pm 31 \mathrm{ml})$. Only presence of sinus rhythm was significant and independent covariate of the difference between CARTO and CT-derived LAVs by multivariate regression analysis.
\end{abstract}

Conclusions: Even though LA volumes evaluated by 3D-electroanatomical mapping have quite good accuracy, the precision is low. For volumes estimated by echocardiography, both precision and accuracy are low.

Keywords: Atrial fibrillation, Echocardiography, Cardiac CT, Left atrial volume, Electroanatomic mapping, Catheter ablation

\section{Background}

Catheter ablation has been established as an effective therapy in selected patients with atrial fibrillation (AF) $[1,2]$. Electroanatomical mapping and $3 \mathrm{D}$ reconstruction of the left atrium (LA) has been introduced as routine method for navigation during catheter ablation for AF. Evaluation of LA size, which has been detected as a predictor of catheter ablation outcome [3, 4], is substantial.

\footnotetext{
* Correspondence: stepan.havranek@lf1.cuni.cz

${ }^{1}$ 2nd Department of Medicine - Department of Cardiovascular Medicine, First Faculty of Medicine, Charles University and General University Hospital, U Nemocnice 2, 12808 Prague, Czech Republic

Full list of author information is available at the end of the article
}

In everyday practice echocardiography is the most dominant method in estimation of LA size. However its predictive value in estimation of real LA volume (LAV) is not optimal [5-10]. Different methods for the assessment of LAV by use of 2D-echocardiography (ECHO) (e.g. area-length, prolate-ellipsoid method or disc method in single or biplane variant) have been introduced $[5-7,11,12]$. Despite these methods are more accurate in estimation of true LA size than isolated LA diameter $[5-7,11,12]$, they still systematically underestimate volumes obtained by 3D-ECHO, CT or MRI [5-10]. Two more studies have shown the substantial disagreement between 2D-ECHO-based LAV and LAV obtained

(c) The Author(s). 2018 Open Access This article is distributed under the terms of the Creative Commons Attribution 4.0 International License (http://creativecommons.org/licenses/by/4.0/), which permits unrestricted use, distribution, and reproduction in any medium, provided you give appropriate credit to the original author(s) and the source, provide a link to the Creative Commons license, and indicate if changes were made. The Creative Commons Public Domain Dedication waiver (http://creativecommons.org/publicdomain/zero/1.0/) applies to the data made available in this article, unless otherwise stated. 
by $3 \mathrm{D}$ electroanatomic mapping and clinical covariates influencing this discrepancies in patients with non-valvular AF $[13,14]$.

In contrast to $2 \mathrm{D}-\mathrm{ECHO}$ indices, some reports have demonstrated high degree of agreement between LA electroanatomical map and CT-assessed LA anatomy [15-17] or 3D echocardiography [18].

There are only limited data about factors that influence the relationship between LAV obtained by electroanatomical mapping and CT. Moreover, previous studies demonstrating correspondence of morphology of LA assessed by $3 \mathrm{D}$ electroanatomical mapping and $\mathrm{CT}$ angiography, have not compared LAV directly [15-17]. We hypothesized that LAV obtained by electroanatomic 3D reconstruction would assess LAV in better agreement with CT than 2D-echocardiography. We also hypothesized that some clinical or morphological characteristics of LA influencing this variance could be detected. We investigated this hypothesis in real-world population of patients with non-valvular AF scheduled for catheter ablation in whom electroanatomic $3 \mathrm{D}$ reconstruction and CT angiography of the LA was performed.

\section{Methods}

Consecutive patients, who were scheduled for first catheter ablation for AF with $\mathrm{CT}$ registration and had complete echocardiographical evaluation of LA size at one cardiology center between May 2013 and December 2015, were included to retrospective analysis. The data were collected in a dedicated registry. The study was approved by the local ethic committee. All patients gave their written informed consent to participate in the study.

\section{Computed tomography}

Computed tomography (CT) was performed in supine position at end-inspiration on a 256-slice CT scanner (Brilliance iCT, Philips Healthcare, Best, The Netherlands) as a prospective ECG-triggered axial (step \& shoot) end-diastolic (78\% of the R-R interval) acquisition. The scan was initiated by bolus tracking with a $180 \mathrm{HU}$ threshold in a region of interest placed in LA during injection of $65 \mathrm{ml}$ of iodinated contrast material (Iomeron 350, Bracco Imaging Deutschland, Germany) at a flow rate of $4.0 \mathrm{ml} / \mathrm{s}$ followed by $60 \mathrm{ml}$ saline chaser at $4.0 \mathrm{ml} / \mathrm{s}$. The acquisition parameters were: tube voltage, $120 \mathrm{kV}$; tube current, $708 \mathrm{~mA}$; collimation, $128 \times 0.625 \mathrm{~mm}$; rotation time, $0.27 \mathrm{~s}$. The images were reconstructed in $0.9 \mathrm{~mm}$ thin sections with $50 \%$ overlap using reconstruction algorithm $\mathrm{XCA}$ and iterative reconstruction technique (iDOSE4, level 4). Raw data were processed by use of dedicated Philips Intelli Space portal. CT LA long and CT LA $\mathrm{L}_{\text {short }}$ were LA diameters measured in apical four chamber projection. LA was then centered on all three cutting planes and CT
LA $_{\text {cranio-caudal }}$ CT LA $A_{\text {antero-posterior }}$ and CT LA transversal diameters were measured. The diameters were obtained as the largest diameter in given projection. $\mathrm{LAV}_{\mathrm{CT}}$ was derived from segmented LA cavity without inclusion of left atrial appendage. Index of sphericity (IS) was calculated with following equation: IS $=(1-$ coefficient of variation of sphere) *100. Coefficient of variation of sphere was defined as average radius standard deviation divided by average radius. Average radius was calculated as mean of radius in three dimensions: antero-posterior, cranio-caudal and transversal [19]. IS was used as marker of atrial remodeling, when data were dichotomized according to median of IS.

\section{D Electroanatomical mapping}

3D electroanatomical mapping of LA was completed in standardized manner at the beginning of whole ablation procedure. We have applied protocol described in previous study [13]. A 3D electroanatomic mapping system (CARTO 3, Biosense-Webster Inc., Diamond Bar, CA, USA) and manual catheter navigation was used for 3D reconstruction of the LA cavity. Uniformly distributed mapping points at end-diastolic phase (time interval from $-150 \mathrm{~ms}$ to $-10 \mathrm{~ms}$ before QRS complex) were acquired at sites with stable endocardial contact. No mapping points behind pulmonary vein ostia were included to the map. Attention was paid to precise delineation of the mitral annulus. The orifice and proximal part of LA appendage was always mapped. Intracardiac echocardiography was used to identify and mark the critical structures. A 3D virtual map of the LA was constructed by software interpolations over the co-ordinates of multiple endocardial tags. LAV $_{\text {CARTO }}$ was calculated using a built-in computational function of the Biosense software prior to merging CARTO and CT reconstruction of atrium.

\section{Echocardiographic examination}

Transthoracic echocardiographic examinations were indicated prior to the catheter ablation according to the guidelines of American Society of Echocardiography 2005 valid at the time of initiation of data collection [12, 20]. The protocol was analogous to previously published methodology [13]. The LA diameter (LAD) was obtained in M-mode and defined as antero-posterior, end-systolic linear dimension in the parasternal long-axis projection using $2 \mathrm{D}$ guidance. The LAV $_{\text {ELLIPSOID }}$ was calculated by the prolate-ellipsoid method, which used three LA orthogonal diameters in ventricular end-systole / atrial diastole (LAD and two orthogonal diameters in the apical 4-chamber view). A standardized biplane disc method (in apical 4-chamber and apical 2-chamber view) was applied to assess $\mathrm{LAV}_{\text {DISC }}$. The tracing of LA cavity was performed without including of pulmonary vein and left atrial appendage. 


\section{Statistical analysis}

Continuous variables were expressed as means with standard deviations after testing for normality (Shapiro-Wilk's test) and compared by the 2-tailed t-test for independent samples. Not normally distributed variables or ordinary data were expressed as medians, interquartile ranges and compared by two-tailed Mann-Whitney $U$ test. Categorical variables were expressed as percentages and compared by $\mathrm{x}^{2}$-test. Pearson's correlation, Bland-Altman analysis and multivariate linear regression (for all univariately different variables with $p \leq 0.2$ ) were used to analyze the relationship between 2D-ECHO-based LAV indices or LAV $_{\text {CARTO }}$ (together with other clinical covariates) as independent variables and $\mathrm{LAV}_{\mathrm{CT}}$ as dependent variable. The difference between correlation coefficients was computed using the r-to-Fisher-z transformation. A $p$-value < 0.05 was considered significant. All analyses were performed using the STATISTICA vers.12 software (Statsoft, Inc., Tulsa, USA).

\section{Results}

One hundred thirty-six patients ablated for AF and had undergone CT prior to intervention were screened to the study. 36 patients were excluded for insufficient echocardiographical data (missing or low quality of recordings). A total 100 patients (aged $63 \pm 8$ years; $71 \%$ males) were analyzed. Paroxysmal AF was manifested in 55 (55\%) patients. Rest of subjects (45\%) had persistent or long-standing persistent AF, respectively. Baseline characteristics of the total population are shown in Table 1 . Females were significantly older than males $66 \pm 8$ vs. ( $62 \pm 8$ years, $p=0.03$ ). Out of all AF classified as non-paroxysmal, only 38 (84\%) were in AF. All patients with AF during CT scan had AF also when $\mathrm{ECHO}$ or electroanatomical mapping were obtained. AF initiated during electroanatomical mapping in 3 (5\%) subjects with SR during CT and ECHO. The distributions of LAV indices are illustrated in Fig. 1.

The results of simple regression between ECHO-based LAV parameters, CARTO based LAV and $\mathrm{LAV}_{\mathrm{CT}}$ are shown in Fig. 2. There was a more positive correlation between $\mathrm{LAV}_{\text {CARTO }}$ and $\mathrm{LAV}_{\mathrm{CT}}$ compared to $\mathrm{LAV}_{\text {DISC }}$ $\operatorname{LAV}_{\mathrm{CT}}(p<0.05)$. The correlation coefficient of LAV ELLIPSOID and $\mathrm{LAV}_{\mathrm{CT}}$ did not differ from coefficient between $\mathrm{LAV}_{\text {CARTO }}$ and LAV $\mathrm{CT}_{\mathrm{CT}}$ or LAV $\mathrm{LISC}_{\mathrm{C}}$ and LAV $\mathrm{CT}_{\mathrm{CT}} \mathrm{LAV}_{\text {ELLIP- }}$ sOID and $\mathrm{LAV}_{\text {DISC }}$ underestimated $\mathrm{LAV}_{\mathrm{CT}}$ with an absolute bias $( \pm 1.96$ standard deviation) of $-55(-108 ;-2)$ $\mathrm{ml}$ and $-39(-102 ;+24) \mathrm{ml}$, respectively. $\operatorname{LAV}_{\text {CARTO }}$ was even more comparable to $\mathrm{LAV}_{\mathrm{CT}}$ with an absolute bias $3.5(-42 ;+43) \mathrm{ml} ; p<0.001$ for difference between indices based on 2D-ECHO LAV and based on LAV CARTO.As depicted in Fig. 3, the bias between LAV $_{\text {DISC }}$ and LAV $_{C T}$ differ according to presence of spherical remodeling of LA (defined as IS above / below median). This sensitivity to
Table 1 Baseline characteristics

\begin{tabular}{|c|c|c|c|}
\hline$N=100$ & $\begin{array}{l}\text { Mean } \pm \text { SD } \\
\text { or } n(\%)\end{array}$ & Median & IQR \\
\hline Age (years) & $63 \pm 8$ & - & - \\
\hline Males & $71(71 \%)$ & - & - \\
\hline Paroxysmal AF & $55(55 \%)$ & - & - \\
\hline Present sinus rhythm & $62(62 \%)$ & - & - \\
\hline Hypertension & $71(71 \%)$ & - & - \\
\hline Diabetes mellitus & $13(13 \%)$ & - & - \\
\hline Structural heart disease & $23(23 \%)$ & - & - \\
\hline Congenital heart disease & $0(0 \%)$ & & \\
\hline $\mathrm{CHADS}_{2}$ score & - & 1 & $1 ; 2$ \\
\hline $\mathrm{CHA}_{2} \mathrm{DS}_{2}$-VASc score & - & 2 & $1 ; 3$ \\
\hline LV EF (\%) & - & 62 & $56 ; 66$ \\
\hline LAVi $\left(\mathrm{ml} / \mathrm{m}^{2}\right)$ & $40 \pm 11$ & - & - \\
\hline CARTO mapping points & $135 \pm 66$ & - & - \\
\hline $\mathrm{ECHO} L A D(P L A X)(\mathrm{mm})$ & $46 \pm 6$ & - & - \\
\hline ECHO LA $A_{\text {long }}(\mathrm{A} 4 \mathrm{C})(\mathrm{mm})$ & $58 \pm 8$ & - & - \\
\hline$E C H O L A_{\text {short }}(A 4 C)(\mathrm{mm})$ & $47 \pm 7$ & - & - \\
\hline$C T L A_{\text {long }}(\mathrm{A} 4 \mathrm{C})(\mathrm{mm})$ & $52 \pm 8$ & - & - \\
\hline$C T L A_{\text {short }}(\mathrm{A} 4 \mathrm{C})(\mathrm{mm})$ & $43 \pm 6$ & - & - \\
\hline$C T L A_{\text {Cranio-caudal }}(\mathrm{mm})$ & $61 \pm 7$ & - & - \\
\hline$C T\left\llcorner A_{\text {Antero-posterior }}(\mathrm{mm})\right.$ & $52 \pm 7$ & - & - \\
\hline $\mathrm{CT}\left\llcorner\mathrm{A}_{\text {Transversal }}(\mathrm{mm})\right.$ & $69 \pm 7$ & - & - \\
\hline LA Sphericity index & $81 \pm 7$ & - & - \\
\hline
\end{tabular}

$A F$ atrial fibrillation; $L V E F$ left ventricular ejection fraction; $L A V i$ left atrial volume indexed to body surface area; $C T$ computed tomography; $L A D$ left atrial diameter in parasternal long-axis view (PLAX); $L A$ - left atrium; A4C Apical four chamber view. $S D$ standard deviation; IQR interquartile range

atrial remodeling was not recognized in $\mathrm{LAV}_{\mathrm{ELLIPSOID}}$ or LAV $_{\text {CARTO. }}$

The differences between LAV derived from CARTO and CT were significantly larger in males, patients without paroxysmal AF and subjects without SR during CT scan in univariate manner (Table 2 and Fig. 4). Other tested clinical parameters (age $>65$ years, arterial hypertension, diabetes, presence of structural heart disease) were not statistically significant. Only presence of SR was significant and independent covariate of the difference between CARTO and CT-derived LAVs by multivariate regression analysis, when all significant and near to significant parameters $(p \leq 0.2)$ in univariate analysis were included (Table 2).

\section{Discussion}

The analysis realized in a real-world population of patients with non-valvular AF verified better agreement between CARTO derived LAV and reference LAV assessed by CT than between 2D-ECHO-based LAV indices and the same reference. The major outcome of the study is 

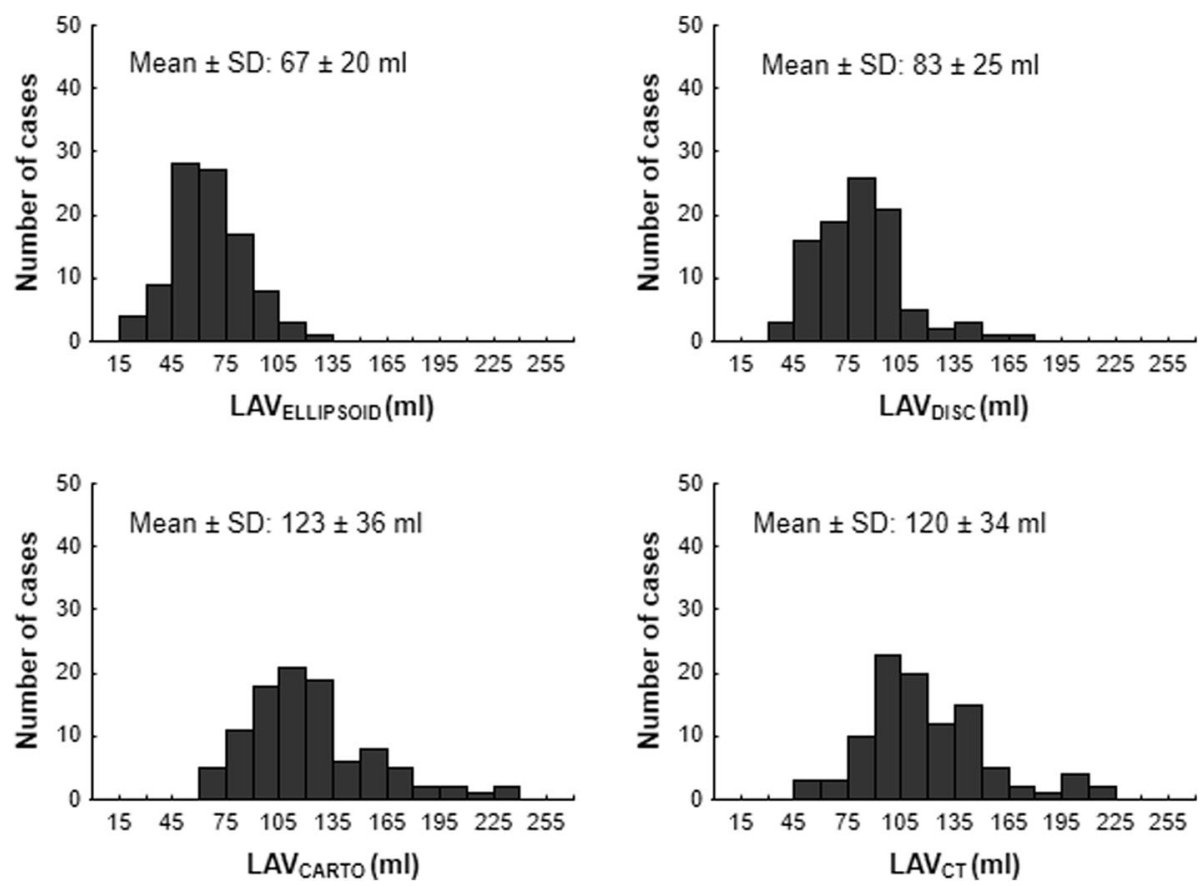

Fig. 1 Distribution of left atrial volumes. Abbreviations: SD - standard deviation; IQR - interquartile range; LAVELLIPSOID - left atrial volume (LAV) assessed by the prolate-ellipsoid method; $L A V_{\text {DISC }}$ - LAV assessed by the biplane disc method; $L A V_{\text {CARTO }}-$ CARTO-derived LAV; LAV $C T$ - LAV assessed by computed tomography
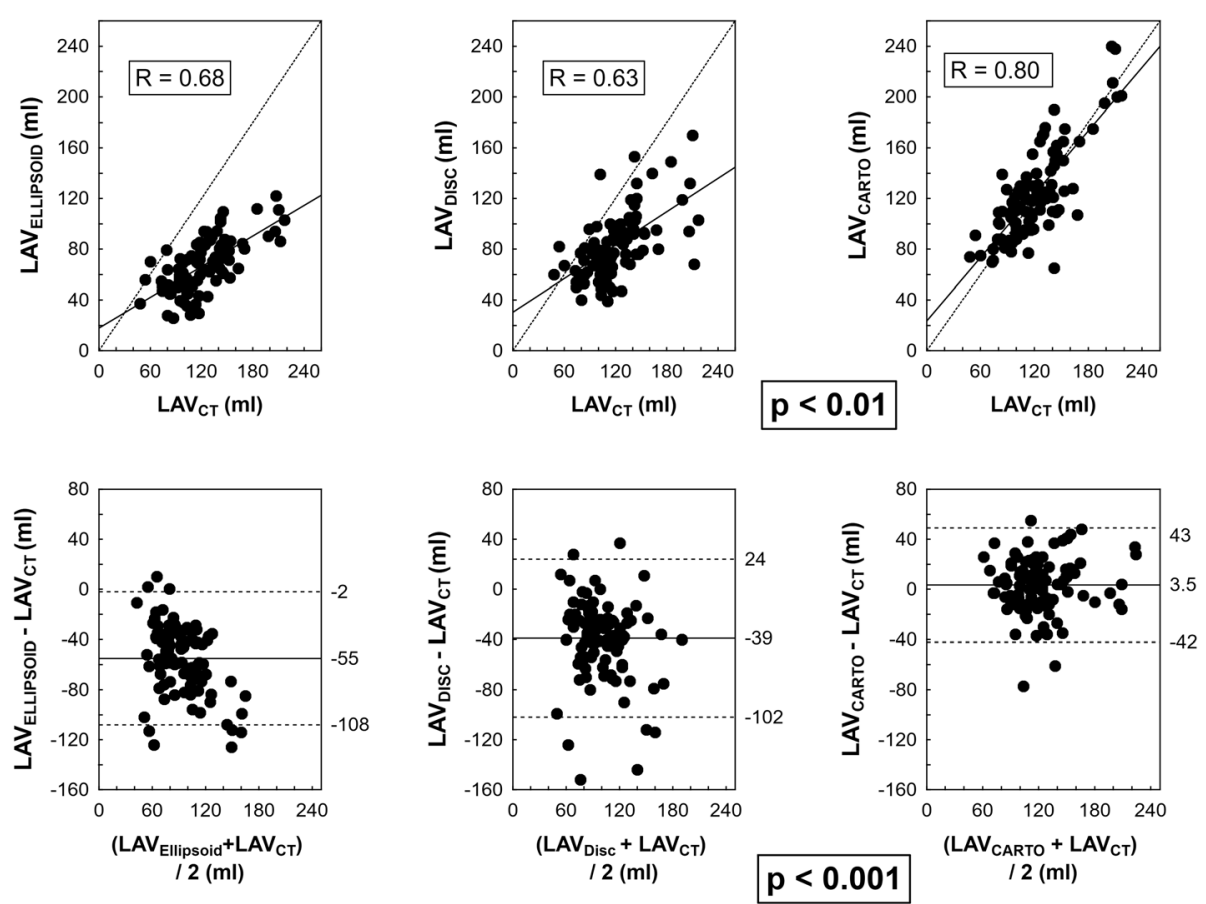

Fig. 2 Correlation and agreement between 2D-ECHO-based, CARTO-derived and CT-derived left atrial volumes. Caption: Upper row: Pearson's correlation. Lower row: scatterplots for absolute differences between 2D-ECHO-based or CARTO-derived LAV versus CT-derived LAV. Abbreviations as in Fig. 1. Upper raw: Dotted line - identity line; full line - regression line. Bottom raw: Full line - bias; dashed line - limits of agreement $( \pm 1.96$ standard deviation). Significance of difference in relationship of 2D-ECHO-based and CARTO-derived to CT-derived volumes is highlighted 


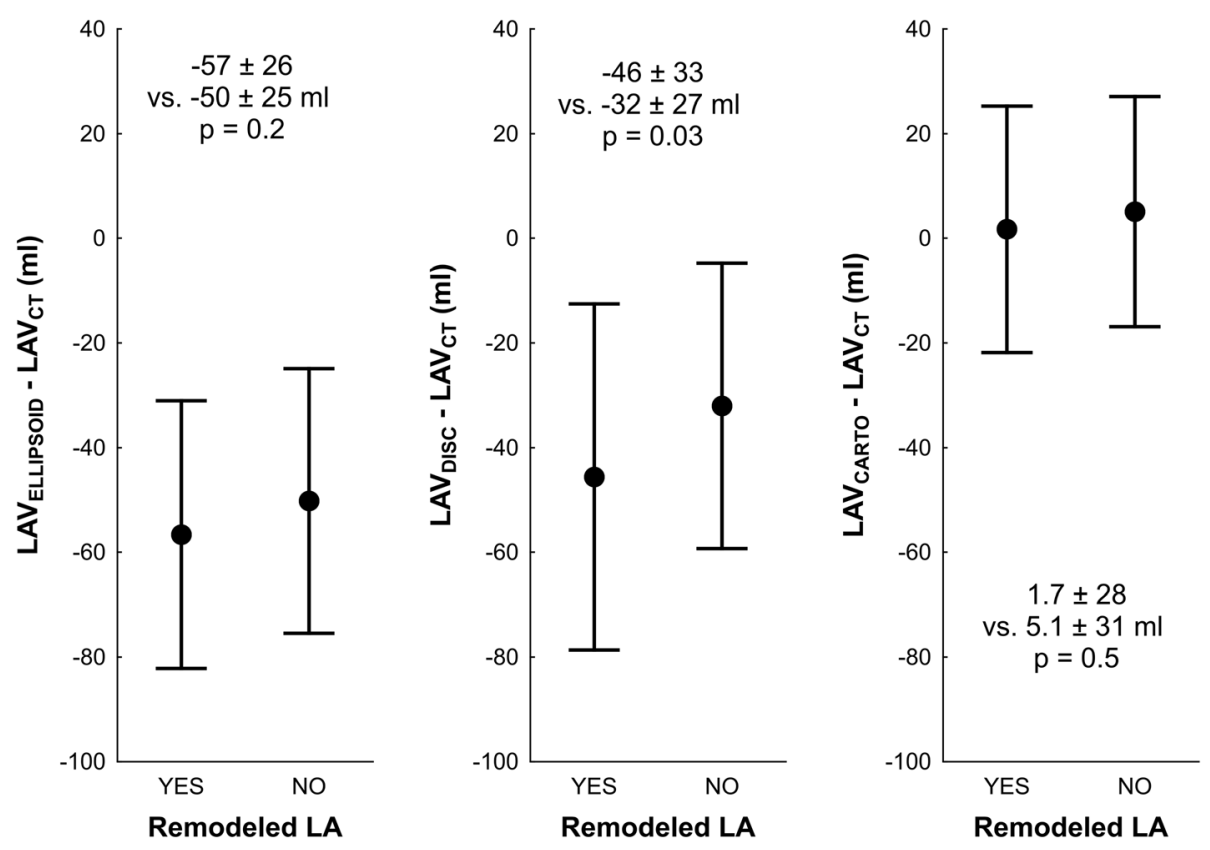

Fig. 3 Differences between 2D-ECHO-based, CARTO-derived and CT-derived left atrial volumes according to remodeling of left atrium. Caption: Left atrium remodeling was defined according to sphericity index obtained from CT. Atrias were dichotomized according to median of sphericity index. The points and whiskers represent mean and \pm standard deviation. Abbreviations as in Fig. 1

that, in contrast to 2D-ECHO-based LAV obtained by disc biplane method, the bias between $\mathrm{LAV}_{\mathrm{CARTO}}$ and $\mathrm{LAV}_{\mathrm{CT}}$ was less sensitive for spherical remodeling. However, despite smaller bias between LAV obtained by CARTO and CT, LA size can be still over- or underestimated by the CARTO. Presence of SR during CT scan was identified as independent covariate in prediction of difference between CARTO and CT derived LAV.

The discrepancy between LA size obtained by various methods has been observed previously. As CT, MRI or 3D-ECHO rectified insight of the LA anatomy as an asymmetrical 3D structure [7-10], the sphericity simplification of echocardiographic methods results in underestimation of the LAV by 2D-ECHO $[5,6,9,12]$, especially in enlarged atria $[6,13]$. Atrial remodeling is associated with a change of LA shape, which caused the standard geometric models even more inaccurate. Such variances include, for example, a trapezoidal LA shape [21], dilatation of the pulmonary vein antrum area [22], LA roof re-shaping [23], enlargement of the anterior portion of the LA [24], and spherical remodeling of the LA [19]. Even the well-validated biplane 2D-based methods, including biplane $\mathrm{LAV}_{\text {DISC }}$ method, systematically underestimated LAV when compared with 3D-ECHO, MRI, CT or CARTO $[9,10,13,14]$.

Even though biplane disc method was allowed in estimation of LAV by previous guidelines [12], the correspondence

Table 2 Univariate and stepwise forward multivariate regression analysis of determinants of discrepancy between left atrial volume obtained by computed tomography and 3D electroanatomical mapping

\begin{tabular}{|c|c|c|c|c|c|}
\hline & \multicolumn{3}{|c|}{ Univariate analysis } & \multicolumn{2}{|l|}{ Multivariate analysis } \\
\hline & YES (ml) & $\mathrm{NO}(\mathrm{ml})$ & $p$ value & Regression coefficient (95\% Cl) & $p$ value \\
\hline Intercept & - & - & - & $7(-3 ; 18)$ & 0.16 \\
\hline Male gender & $6.4 \pm 23$ & $-3.8 \pm 19$ & 0.04 & $5(-1 ; 18)$ & 0.08 \\
\hline Paroxysmal AF & $-1.4 \pm 22$ & $9.4 \pm 22$ & 0.02 & $-5(-16 ; 6)$ & 0.34 \\
\hline Age $>65$ years & $-0.8 \pm 22$ & $6.0 \pm 23$ & 0.15 & $-0.1(-0.7 ; 0.4)$ & 0.67 \\
\hline Arterial hypertension & $1.6 \pm 23$ & $8.1 \pm 21$ & 0.20 & $-5(-15 ; 6)$ & 0.36 \\
\hline Diabetes mellitus & $-3.5 \pm 22$ & $4.9 \pm 21$ & 0.18 & $8(-6 ; 21)$ & 0.27 \\
\hline Structural heart disease & $-3.6 \pm 28$ & $5.7 \pm 20$ & 0.09 & $-9(-20 ; 2)$ & 0.09 \\
\hline SR during $C T$ & $-1.1 \pm 23$ & $11.3 \pm 20$ & 0.008 & $-12(-21 ;-3)$ & 0.008 \\
\hline
\end{tabular}

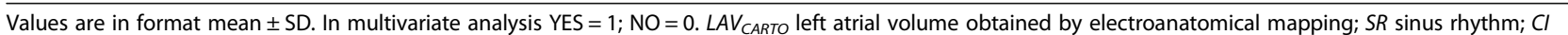
confidence interval 

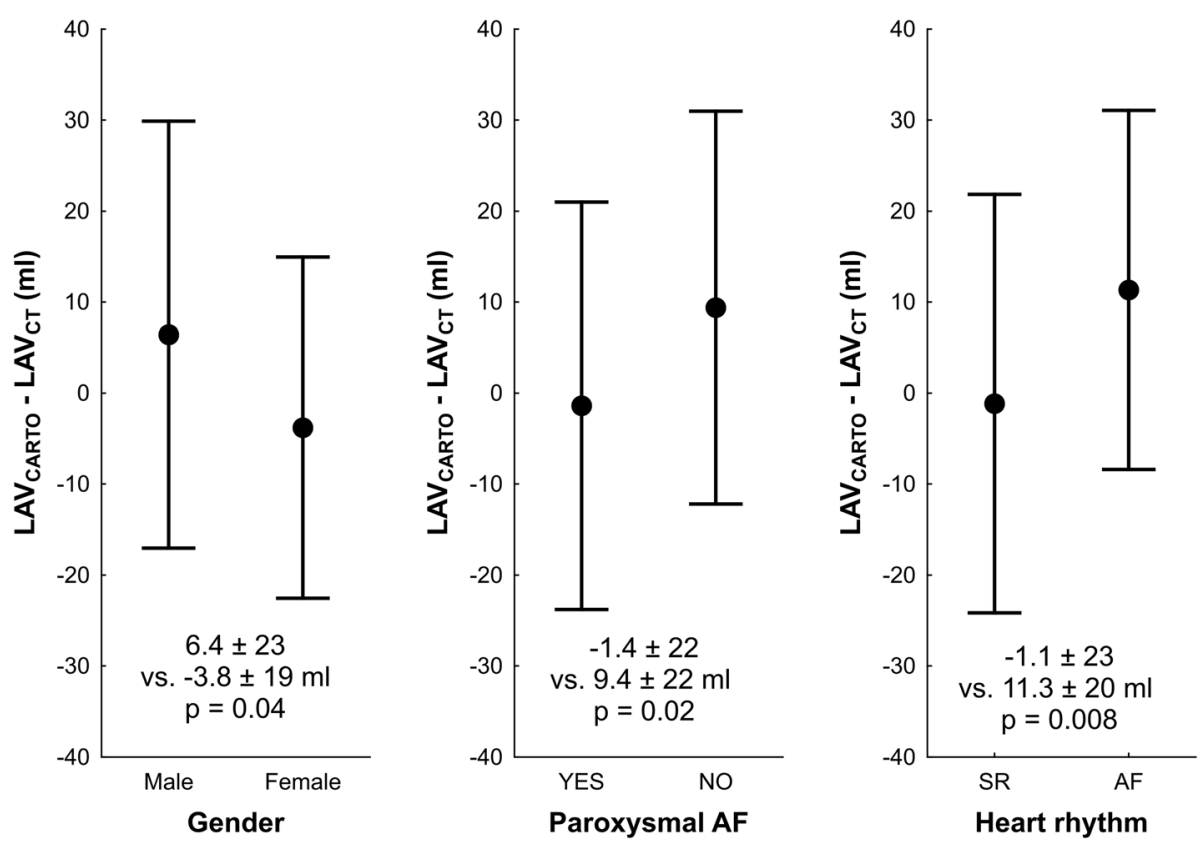

Fig. 4 Differences between CARTO-derived and CT-derived left atrial volumes according to clinical covariates. Caption: The points and whiskers represent mean and \pm standard deviation. Abbreviations as in Fig. 1

of $\mathrm{LAV}_{\text {DISC }}$ to $\mathrm{LAV}_{\mathrm{CT}}$ had been low and still dependent on spherical remodeling demonstrated by simplified IS. It responds to expectation that the missing of constant proportions between the orthogonal axes in remodeled and spherically deformed LA more likely affect LA size parameters based on geometrical models (including 2D-ECHO derived methods) instead of direct measurement.

In contrast to disc biplane method, bias between $\mathrm{LAV}_{\text {ELLIPSOID }}$ and $\mathrm{LAV}_{\mathrm{CT}}$ was not changed significantly when LA atrium was spherically remodeled. This phenomenon stays in parallel to our previously published data, where the prolate-ellipsoid method based on composition of three linear dimensions provided modestly better correlation with LAV obtained by electroanatomical mapping (i.e. CARTO) and, consequently, better prediction of LA enlargement than LAV based on planimetry [13]. However, an ellipsoid model demonstrated still low accuracy (large underestimation) of $\mathrm{LAV}_{\mathrm{CT}}$. This finding stays in agreement with previous studies systematically identifying smaller LAV obtained by the prolate-ellipsoid method compared with $3 \mathrm{D}-\mathrm{ECHO}$ or CARTO [6, 13, 25, 26].

High level of concordance between CT-assessed LA anatomy and LA CARTO maps has been already identified $[15,16]$. LA shape assessment by electroanatomic mapping has also been shown to have acceptable correspondence to LAV assessed by intra-procedural 3D cone-beam CT angiogram [17]. In contrast to our data, all previously published studies have evaluated the relationships between linear dimensions [15] or surface-to-point distance $[16,17]$, instead to direct comparison of measured atrial volumes. Since LAV has been introduced as preferred parameter in LA size estimation, reevaluation of accuracy and precision of different methods of LAV assessment had become to be more relevant. Even though our study had found strong correlation $(r=0.8)$ between CARTO and the CT-derived LAV, the error reached relative range $\sim 30 \%$. The existence of wide range of agreement between LAV derived by CARTO and CT is novel finding. Moreover, in patients without SR during CT scan and electroanatomical mapping, overestimation of $\mathrm{LAV}_{\mathrm{CT}}$ is more likely present. On the other hand, 3D electroanatomical reconstruction was insensitive to spherical deformation, when compared to biplane disc echocardiographic method.

In purposed study, dense, point-by-point electroanatomic LA reconstructions were built. All electroanatomical LA maps were created by experienced physicians. In case of high-density mapping, isolated inaccuracies in location of single points are usually mutually nullified, so high level of reproducibility would be presented. However, the volume of CARTO map is still dependent on how considerable segment of pulmonary vein antra, left atrial appendage, atrial region closed to mitral annulus is included to 3D reconstruction and how much stretch is applied on mobile interatrial septum leading to increase atrial volume. We speculate, that in case of advanced type of AF, especially when arrhythmia is ongoing, the $3 \mathrm{D}$ electroanatomical map is created more precisely in intention to identify more proarrhythmogenic substrate. This could be the most likely explanation for overestimation 
of $L A V_{C T}$ by $L A V_{\text {CARTO }}$ in case of absence of SR. This is in discrepancy with one previous small study showing that the heart rhythm has not influenced accuracy of fusion between CT and 3D electroanatomical map [16].

More indices describing LA shape remodeling have been introduced as predictors of effectiveness of catheter ablation $[19,27]$ or arrhythmia recurrence after DC cardioversion [28]. Site to IS, the asymmetry index describing ratio between volume of anterior portion of LA and total LAV has been proved as better prognostic tool [27]. For purpose of this technical study IS was chosen as marker of atrial remodeling as more simple method with high level of reproducibility.

The results of purposed study were partially presented as conference abstract at Euro Heart Care 2017 [29].

\section{Study limitations}

The study has several limitations. First, it was retrospectively designed. The data collection was not independently monitored. Second, the study was single center study. Third, the time lag between imaging procedure and electroanatomical mapping was from one to three days in our study. However, it has been shown, that time lag less than 4 days from CT to electroanatomical mapping was the most likely not the factor responsible for integration error [17]. Only 3 patients manifested different rhythms among modalities. Fourth, LAV was acquired in different phase among the modalities. Both CT and CARTO obtained data in end-diastole. In contrast, ECHO used ventricular end-systole. Since diameters and planimetry are measured just before opening of mitral valve, atrial size should be maximal at this phase. We therefore speculate that underestimation of LAV by $\mathrm{ECHO}$ is not given by differences of time span of data acquisition. If the same phase of the heart cycle was used, underestimation of LAV with echocardiography would increase. If CT and CARTO were performed in systole their values would be larger than in diastole and hence bias would increase compared to echocardiography.

Finally, the results are valid in patients with non-valvular $\mathrm{AF}$ and cannot be probably converted to general population as well as to patients with valvular AF (severe mitral regurgitation or stenosis, presence of mitral valve prosthesis).

\section{Conclusions}

Even though LA volumes evaluated by electroanatomical mapping have quite good accuracy, the precision is low. For volumes estimated by echocardiography, both precision and accuracy are low. The electroanatomical mapping is less sensitive to inaccuracy of LAV estimation predominantly driven by the magnitude of LA spherical remodeling. Referred bias between CT and CARTO-derived volumes is related to existence of sinus rhythm.

\section{Abbreviations}

A4C: Apical four chamber view; AUC: Area under the curve; Cl: Confidence interval; CT: Computed tomography; IQR: Interquartile range; IS: Index of sphericity; LA: Left atrium; LAD: Left atrial diameter in parasternal long-axis

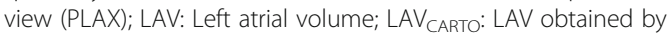
electroanatomical mapping; $L A V_{C T}$ : LAV assessed by computed tomography; LAV DISc: LAV assessed by the biplane disc method; LAV ELLIPSOID: LAV assessed by the prolate-ellipsoid method; LAVi: LAV indexed to body surface area; LV EF: Left ventricular ejection fraction; SD: Standard deviation; SR: Sinus rhythm

\section{Acknowledgments}

The results of purposed study were partially presented as conference abstract at Euro Heart Care 2017. We thank Hana Fingrova for her help with language correction. The study was supported by Progres Q38/LF1 and by project reg. no. CZ.2.16/3.1.00/21565 from OP Prague Competitiveness.

\section{Funding}

The work was supported by the following: Charles University supporting program: Progres Q38/LF1; and OP Prague Competitiveness: CZ.2.16/3.1.00/ 21565. The funders had no role in study design, data collection and analysis, decision to publish, or preparation of the manuscript.

Availability of data and materials

All relevant data are within the paper. The datasets analyzed in this study are also available from the corresponding author on request.

\section{Authors' contributions}

ZF coordinated the study, performed data analysis, participated in statistical analysis and prepared the manuscript. JM performed data analysis, and participated in critically revising the manuscript for important intellectual content. SH conceived the study, participated in data analysis, statistical analysis and drafted the manuscript as corresponding author. LL performed data acquisition, data analysis, participated in study design and helped to draft the manuscript. PK critically revising the manuscript and participated in data analysis. AL participated in critically revising the manuscript for important intellectual content, conceived of the study, participated in its design and helped to draft the manuscript. All authors read and approved the final manuscript.

Ethics approval and consent to participate

This study was approved by the Ethics Committees General University Hospital in Prague. All subjects provided written informed consent before the study.

\section{Consent for publication}

Not applicable.

\section{Competing interests}

The authors declare that they have no competing interests.

\section{Publisher's Note}

Springer Nature remains neutral with regard to jurisdictional claims in published maps and institutional affiliations.

\section{Author details}

${ }^{1}$ 2nd Department of Medicine - Department of Cardiovascular Medicine, First Faculty of Medicine, Charles University and General University Hospital, U Nemocnice 2, 12808 Prague, Czech Republic. Department of Radiology, First Faculty of Medicine, Charles University and General University Hospital, U Nemocnice 2, Prague 128 08, Czech Republic.

Received: 29 August 2017 Accepted: 13 September 2018

Published online: 18 September 2018

\section{References}

1. Calkins H, Kuck KH, Cappato R, Brugada J, Camm AJ, Chen SA, et al. 2012 HRS/EHRA/ECAS expert consensus statement on catheter and surgical ablation of atrial fibrillation: recommendations for patient selection, procedural techniques, patient management and follow-up, definitions, endpoints, and research trial design. Europace. 2012;14:528-606. 
2. Kirchhof P, Benussi S, Kotecha D, Ahlsson A, Atar D, Casadei B, et al. 2016 ESC Guidelines for the management of atrial fibrillation developed in collaboration with EACTS. Eur Heart J. 2016;37:2893-962.

3. Berruezo A, Tamborero D, Mont L, Benito B, Tolosana JM, Sitges M, et al. Pre-procedural predictors of atrial fibrillation recurrence after circumferential pulmonary vein ablation. Eur Heart J. 2007;28:836-41.

4. von Bary C, Dornia C, Eissnert C, Nedios S, Roser M, Hamer OW, et al. Predictive value of left atrial volume measured by non-invasive cardiac imaging in the treatment of paroxysmal atrial fibrillation. J Interv Card Electrophysiol. 2012;34:181-8.

5. Lang RM, Badano LP, Mor-Avi V, Afilalo J, Armstrong A, Ernande L, et al. Recommendations for cardiac chamber quantification by echocardiography in adults: an update from the American Society of Echocardiography and the European Association of Cardiovascular Imaging. J Am Soc Echocardiogr. 2015;28:1-39.

6. Badano LP, Pezzutto N, Marinigh R, Cinello M, Nucifora G, Pavoni D, et al. How many patients would be misclassified using M-mode and two-dimensional estimates of left atrial size instead of left atrial volume? A three-dimensional echocardiographic study. J Cardiovasc Med. 2008:9:476-84.

7. Hof I, Arbab-Zadeh A, Scherr D, Chilukuri K, Dalal D, Abraham T, et al. Correlation of left atrial diameter by echocardiography and left atrial volume by computed tomography. J Cardiovasc Electrophysiol. 2009;20:159-63.

8. Vandenberg BF, Weiss RM, Kinzey J, Acker M, Stark CA, Stanford W, et al. Comparison of left atrial volume by two-dimensional echocardiography and cine-computed tomography. Am J Cardiol. 1995;75:754-7.

9. Rodevan O, Bjornerheim R, Ljosland M, Maehle J, Smith HJ, Ihlen H. Left atrial volumes assessed by three- and two-dimensional echocardiography compared to MRI estimates. Int J Card Imaging. 1999;15:397-410.

10. Mor-Avi V, Yodwut C, Jenkins C, Kuhl H, Nesser HJ, Marwick TH, et al. Realtime 3D echocardiographic quantification of left atrial volume: multicenter study for validation with CMR. JACC Cardiovasc Imaging. 2012;5:769-77.

11. Lester SJ, Ryan EW, Schiller NB, Foster E. Best method in clinical practice and in research studies to determine left atrial size. Am J Cardiol. 1999;84:829-32.

12. Lang RM, Bierig M, Devereux RB, Flachskampf FA, Foster E, Pellikka PA, et al. Recommendations for chamber quantification: a report from the American Society of Echocardiography's guidelines and standards committee and the chamber quantification writing group, developed in conjunction with the European Association of Echocardiography, a branch of the European Society of Cardiology. J Am Soc Echocardiogr. 2005;18:1440-63.

13. Havranek S, Fiala M, Bulava A, Sknouril L, Dorda M, Bulkova V, et al. Multivariate analysis of correspondence between left atrial volumes assessed by echocardiography and 3-dimensional Electroanatomic mapping in patients with atrial fibrillation. PLoS One. 2016;11. https://doi.org/10.1371/ journal.pone.0152553.

14. Sknouril L, Havranek S, Bulkova V, Dorda M, Palecek T, Simek J, et al. Disparity between two-dimensional echocardiographic and electroanatomic left and right atrial volumes in patients undergoing catheter ablation for long-standing persistent atrial fibrillation. Physiol Res. 2017;66:241-9.

15. Piorkowski C, Hindricks G, Schreiber D, Tanner H, Weise W, Koch A, et al. Electroanatomic reconstruction of the left atrium, pulmonary veins, and esophagus compared with the "true anatomy" on multislice computed tomography in patients undergoing catheter ablation of atrial fibrillation. Heart Rhythm. 2006;3:317-27.

16. Martinek M, Nesser HJ, Aichinger J, Boehm G, Purerfellner H. Accuracy of integration of multislice computed tomography imaging into threedimensional electroanatomic mapping for real-time guided radiofrequency ablation of left atrial fibrillation-influence of heart rhythm and radiofrequency lesions. J Interv Card Electrophysiol. 2006;17:85-92.

17. Ejima K, Shoda M, Yagishita D, Futagawa K, Yashiro B, Sato T, et al. Image integration of three-dimensional cone-beam computed tomography angiogram into electroanatomical mapping system to guide catheter ablation of atrial fibrillation. Europace. 2010;12:45-51.

18. Muller H, Burri H, Gentil P, Lerch R, Shah D. Measurement of left atrial volume in patients undergoing ablation for atrial fibrillation: comparison of angiography and electro-anatomic (CARTO) mapping with real-time threedimensional echocardiography. Europace. 2010;12:792-7.

19. Bisbal F, Guiu E, Calvo N, Marin D, Berruezo A, Arbelo E, et al. Left atrial sphericity: a new method to assess atrial remodeling. Impact on the outcome of atrial fibrillation ablation. J Cardiovasc Electrophysiol. 2013;24:752-9.
20. Douglas PS, Garcia MJ, Haines DE, Lai WW, Manning WJ, Patel AR, et al. ACCF/ASE/AHA/ASNC/HFSA/HRS/SCAI/SCCM/SCCT/SCMR 2011 appropriate use criteria for echocardiography. J Am Soc Echocardiogr. 2011;24:229-67.

21. Cozma D, Popescu BA, Lighezan D, Lucian P, Mornos C, Ginghina C, et al. Left atrial remodeling: assessment of size and shape to detect vulnerability to atrial fibrillation. Pacing Clin Electrophysiol 2007;30 Suppl 1:S147-50.

22. Tsao HM, Yu WC, Cheng HC, Wu MH, Tai CT, Lin WS, et al. Pulmonary vein dilation in patients with atrial fibrillation: detection by magnetic resonance imaging. J Cardiovasc Electrophysiol. 2001;12:809-13.

23. Kurotobi T, Iwakura K, Inoue K, Kimura R, Toyoshima Y, Ito N, et al. The significance of the shape of the left atrial roof as a novel index for determining the electrophysiological and structural characteristics in patients with atrial fibrillation. Europace. 2011;13:803-8.

24. Nedios S, Tang M, Roser M, Solowjowa N, Gerds-Li JH, Fleck E, et al. Characteristic changes of volume and three-dimensional structure of the left atrium in different forms of atrial fibrillation: predictive value after ablative treatment. J Interv Card Electrophysiol. 2011;32:87-94.

25. Nikitin NP, Witte KK, Thackray SD, Goodge LJ, Clark AL, Cleland JG. Effect of age and sex on left atrial morphology and function. Eur J Echocardiogr. 2003;4:36-42.

26. Ujino K, Barnes ME, Cha SS, Langins AP, Bailey KR, Seward JB, et al. Twodimensional echocardiographic methods for assessment of left atrial volume. Am J Cardiol. 2006;98:1185-8.

27. Nedios S, Koutalas E, Kosiuk J, Sommer P, Arya A, Richter S, et al. Impact of asymmetrical dilatation of the left atrium on the long-term success after catheter ablation of atrial fibrillation. Int J Cardiol. 2015;184:315-7.

28. Osmanagic A, Moller S, Osmanagic A, Sheta HM, Vinther KH, Egstrup K. Left atrial Sphericity index predicts early recurrence of atrial fibrillation after direct-current cardioversion: an echocardiographic study. Clin Cardiol. 2016; 39:406-12.

29. Fingrova Z, Havranek S, Marek J, Lambert L, Linhart A. Correspondence between left atrial size estimated by echocardiography, $C T$ and electroanatomical mapping in patients with atrial fibrillation. EuroHeartCare 2017. European Journal of Cardiovasc Nursing. 2017;16 Suppl. 1:S79.

\section{Ready to submit your research? Choose BMC and benefit from:}

- fast, convenient online submission

- thorough peer review by experienced researchers in your field

- rapid publication on acceptance

- support for research data, including large and complex data types

- gold Open Access which fosters wider collaboration and increased citations

- maximum visibility for your research: over $100 \mathrm{M}$ website views per year

At BMC, research is always in progress.

Learn more biomedcentral.com/submissions 